Vol. 1 No. 1, Feb 2021, hlm. 45 - 50

DOI: https://doi.org/10.33330/.v1i1.1028

Available online at http:// jurnal.stmikroyal.ac.id/index.php/jutsi

\title{
PENERAPAN E-CRM DALAM MENINGKATKAN PELAYANAN PELANGGAN PADA RUMAH JAMUR SILAU LAUT
}

\author{
Mugi Kasih Lestari ${ }^{1}$, Bachtiar Efendi ${ }^{*}$, Endra Saputra ${ }^{3}$ \\ ${ }^{1}$ Mahasiswa Prodi Sistem Informasi, STMIK Royal \\ ${ }^{2}$ Prodi Sistem Komputer, STMIK Royal \\ ${ }^{3}$ Prodi Manajemen Informatika, STMIK Royal \\ *email: youngthady@gmail.com
}

\begin{abstract}
Silau LautMushroom House is a medium-sized enterprise located in the Silau Laut subdistrict. Engaged in sales, Silau LautMushroom House provides fresh oyster mushrooms in various packaging sizes. So far, Silau LautMushroom House still uses a manual system in managing sales and purchasing data. Buyers still have trouble knowing the available mushroom stocks. Along with the times, Silau LautMushroom House wants its business to grow and be able to beat its competitors by using one of the customer-oriented business strategies or what is known as CRM (Customer Relationship Management) so that it can introduce Silau LautMushroom House to all people in the community to expand its reach. marketing with the aim of increasing sales and providing maximum service to customers.
\end{abstract}

Keywords: CRM; Oyster Mushroom; Sublime Text 3; PHP and MySQL.

Abstrak:Rumah Jamur Silau Laut merupakan sebuah usaha menengah yang terletak di kecamatan Silau Laut. Bergerak di bidang penjualan, Rumah Jamur Silau Laut menyediakan jamur tiram segar dalam berbagai ukuran kemasan. Selama ini Rumah Jamur Silau Laut masih menggunakan sistem manual dalam mengelola data penjualan dan data pembelian. Pembeli masih kesulitan mengetahui stok jamur yang tersedia. Seiring perkembangan zaman Rumah Jamur Silau Laut ingin bisnisnya berkembang dan dapat mengalahkan pesaing-pesaingnya dengan menggunakan salah satu strategi bisnis yang berorientasi pada pelanggan atau disebut dengan istilah CRM (Customer Relationship Management) sehingga dapat memperkenalkan Rumah Jamur Silau Laut kepada semua kalangan masyarakat untuk memperluas jangkauan pemasaran dengan tujuan dapat meningkatkan penjualan serta memberikan pelayanan kepada pelanggan secara maksimal.

Kata kunci : CRM; Jamur Tiram; Sublime Text 3; PHP dan MySQL

\section{PENDAHULUAN}

Jamur tiram selaku salah satu bahan pangan telah lumayan lama diketahui oleh warga, baik golongan ekonomi menengah atas ataupun dasar. Jamur pula tercantum sebagai komoditas pertanian organik, sebab proses budidayanya tidak memakai pupuk sintesis maupun bahan kimia yang lain. Keunggulan inilah yang menjadikan jamur terus di gemari serta menjadi opsi terbaik buat dibudidayakan oleh warga [1]. 
Vol. 1 No. 1, Feb 2021, hlm. 45 - 50

DOI: https://doi.org/10.33330/.v1i1.1028

Available online at http:// jurnal.stmikroyal.ac.id/index.php/jutsi

Rumah Jamur Silau Laut merupakan sebuah industri rumahan yang melayani penjualan jamur tiram putih segar. Rumah Jamur Silau Laut masih menggunakan media penjualan tradisional sehingga komunikasi antara penjual dengan pembeli sangatlah terbatas dan pelayanan pelanggan masih belum maksimal.

Masalah yang dihadapi oleh Rumah Jamur Silau Laut adalah dibutuhkan sebuah sistem informasi berbasis web (online), yang mana sistem tersebut mampu memberikan informasi kepada customer meliputi pemesanan jamur, data stok jamur, harga jamur, dan informasi lainnya mengenai jamur tiram serta diintegrasikan dengan suatu database yang dapat menyimpan data-data yang diperlukan.

Sistem ini dibuat untuk memberikan pelayanan kepada customer seperti menu chat yang mana customer dapat bertanya langsung kepada admin seputar jamur tiram. Hal ini dilakukan untuk memberikan kepuasan kepada pelanggan atas pelayanan dari sistem yang dibuat. Sistem ini dibuat menggunakan metode CRM. Defenisi dari CRM (Customer Relationship Management ) itu sendiri adalah salah satu upaya perusahaan dalam mengelola pelanggan yang dimiliki secara lebih optimal [2].

Perihal ini sangatlah berarti karna dengan. terdapatnya suatu sistem ini akan bisa menolong hambatan yang ada. Konsep Customer Relationship Management (CRM) muncul berdasarkan konsep Relationship Marketing. Dalam Relationship Marketing perusahaan selalu berusaha untuk menjalin kerja sama dan hubungan dengan seluruh pihak yang berkepentingan untuk mencapai tujuan bersama [3]. Adapun data pelanggan yang setiap hari melakukan pemesanan jamur yaitu saudari sekar.

Jumlah pemesannannya hingga 7,5 kg, dipasarkan dalam bentuk kemas-an berukuran 125 gram, tujuan pemasarannya yaitu pasar Tanjung Balai. Berikutnya saudari mariani, jumlah pemesanannya $1 \mathrm{~kg}$, dipasarkan dalam bentuk kemas-an berukuran 100 gram, tujuan pemasarannya yaitu pasar Punggulan. Selanjutnya saudari Eli, jumlah pemesanannya $6 \mathrm{~kg}$, dipasarkan dalam bentuk kemasan berukuran 100 gram dan tujuan penjualannya yaitu pasar Air Joman. Selanjutnya saudari Nining dengan jumlah pemesanan $1 \mathrm{~kg}$, dipasarkan dalam bentuk kemasan berukuran 100 gram dan tujuannya ke pasar Air Joman. Selanjutnya saudari Marsinah dengan jumlah pemesanan $2 \mathrm{~kg}$, dipasarkan dalam bentuk kemasan berukuran 100 gram dan dijual keliling. Selanjutnya saudari sukar dengan pemesanan $2 \mathrm{~kg}$, dipasarkan dalam bentuk kemasan berukuran 100 gram dan tujuannya ke pasar Air Joman.

Data di atas diambil pada 1 minggu terakhir di bulan Juni, banyaknya jumlah pesanan tergantung dengan banyaknya jumlah jamur yang dipanen. Data pelanggan di atas hanya pelanggan yang melakukan pemesanan setiap harinya, namun masih banyak lagi pelanggan yang bergantian setiap harinya membeli langsung ke lokasi Rumah Jamur Silau Laut.

\section{METODE}

Customer Relationship Management adalah salah satu metode industri dalam mengelola pelanggan mereka secara lebih optimal. CRM fokus pada pengelolaan serta kenaikan ikatan antara industri dengan pelanggan [4]. Berawal dari ikatan yang baik antara pelanggan dengan industri sehingga bakal menyokong industri melaksanakan perkembangan.

CRM merupakan sebuah strategi dan metodologi yang dipadukan dengan pemanfaatan teknologi informasi berupa perangkat lunak computer (software) dan perangkat keras computer (hardware), untuk membantu perusahaan di dalam mengelola 
Vol. 1 No. 1, Feb 2021, hlm. 45 - 50

DOI: https://doi.org/10.33330/.v1i1.1028

Available online at http:// jurnal.stmikroyal.ac.id/index.php/jutsi

pelanggan mereka dan menjaga hubungan baik dengan pelanggan, agar dapat mencapai tujuan bisnis perusahaan.

\section{HASIL DAN PEMBAHASAN}

Berikut data pembelian pelanggan Rumah Jamur Silau Laut yang diambil pada satu minggu awal bulan Oktober.

Tabel 1. Data Jamur pada Satu Minggu Awal Bulan Oktober

\begin{tabular}{|c|c|l|c|c|}
\hline No & Tanggal & Nama Pelanggan & Kemasan Jamur & Jumlah Produk \\
\hline 1 & $1 / 10 / 2020$ & Mariani & $100 \mathrm{gr}$ & 20 \\
\hline 2 & $1 / 10 / 2020$ & Kijo & $125 \mathrm{gr}$ & 67 \\
\hline 3 & $1 / 10 / 2020$ & Sekar & $125 \mathrm{gr}$ & 50 \\
\hline 4 & $1 / 10 / 2020$ & Gino & $100 \mathrm{gr}$ & 10 \\
\hline 5 & $2 / 10 / 2020$ & Kijo & $125 \mathrm{gr}$ & 58 \\
\hline 6 & $2 / 10 / 2020$ & Sekar & $125 \mathrm{gr}$ & 50 \\
\hline 7 & $3 / 10 / 2020$ & Asnari & $125 \mathrm{gr}$ & 15 \\
\hline 8 & $3 / 10 / 2020$ & Nining & $100 \mathrm{gr}$ & 10 \\
\hline 9 & $3 / 10 / 2020$ & Eli & $100 \mathrm{gr}$ & 50 \\
\hline 10 & $3 / 10 / 2020$ & Marsinah & $100 \mathrm{gr}$ & 10 \\
\hline 11 & $3 / 10 / 2020$ & Sukar & $100 \mathrm{gr}$ & 20 \\
\hline 12 & $3 / 10 / 2020$ & Kijo & $125 \mathrm{gr}$ & 67 \\
\hline 13 & $3 / 10 / 2020$ & Sekar & $125 \mathrm{gr}$ & 40 \\
\hline 14 & $3 / 10 / 2020$ & Gino & $100 \mathrm{gr}$ & 10 \\
\hline 15 & $4 / 10 / 2020$ & Kijo & $125 \mathrm{gr}$ & 62 \\
\hline 16 & $4 / 10 / 2020$ & Sekar & $125 \mathrm{gr}$ & 50 \\
\hline 17 & $4 / 10 / 2020$ & Gino & $100 \mathrm{gr}$ & 10 \\
\hline 18 & $5 / 10 / 2020$ & Mariani & $100 \mathrm{gr}$ & 20 \\
\hline 19 & $5 / 10 / 2020$ & Kijo & $125 \mathrm{gr}$ & 70 \\
\hline 20 & $5 / 10 / 2020$ & Gino & $100 \mathrm{gr}$ & 10 \\
\hline 21 & $6 / 10 / 2020$ & Asnari & $125 \mathrm{gr}$ & 15 \\
\hline 22 & $6 / 10 / 2020$ & Eli & $100 \mathrm{gr}$ & 50 \\
\hline 23 & $6 / 10 / 2020$ & Marsinah & $100 \mathrm{gr}$ & 10 \\
\hline 24 & $6 / 10 / 2020$ & Sukar & $100 \mathrm{gr}$ & 20 \\
\hline 25 & $6 / 10 / 2020$ & Kijo & $125 \mathrm{gr}$ & 46 \\
\hline 26 & $6 / 10 / 2020$ & Sekar & $100 \mathrm{gr}$ & 50 \\
\hline 27 & $6 / 10 / 2020$ & Gino & $125 \mathrm{gr}$ & 10 \\
\hline 28 & $7 / 10 / 2020$ & Nining & $125 \mathrm{gr}$ & 10 \\
\hline 29 & $7 / 10 / 2020$ & Marsinah & & 40 \\
\hline 30 & $7 / 10 / 2020$ & Kijo & & 10 \\
\hline 31 & $7 / 10 / 2020$ & Sekar & Gr & \\
\hline 32 & $7 / 10 / 2020$ & Gino & & 10 \\
\hline & & & & 100 \\
\hline
\end{tabular}


Vol. 1 No. 1, Feb 2021, hlm. 45 - 50

DOI: https://doi.org/10.33330/.v1i1.1028

Available online at http:// jurnal.stmikroyal.ac.id/index.php/jutsi

\section{Analisis Proses}

Sistem Customer Relationship Management pada rumah jamur ini menerapkan fiturfitur seperti media chat. Media chat digunakan pelanggan untuk berkomunikasi berbentuk teks dengan admin rumah jamur.Selanjutnya dengan menerapkan fitur rating yang berfungsi untuk memberi nilai untuk pelayanan website rumah jamur dan kualitas jamur yang dijual tersebut.

Setelah pelanggan melakukan pemesanan maka pelanggan dapat menginputkan rating tersebut kemudian menerapkan fitur give away pada webiste tersebut. Fitur give away yaitu jika pelanggan melakukan pemesanan atau pembelian sebanyak 10 kali maka pelanggan akan mendapatkan bonus dari admin rumah jamur. Sistem penjualan online dengan menggunakan bahasa pemrograman $P H P$ dan MySQL sebagai database server dapat memudahkan pelanggan dalam hal pemesanan jamur [5].

\section{Menu Publik dan Mendaftarkan Akun}

Menu publik merupakan menu yang pertama tampil ketika user membuka website rumah jamur silau laut. Dan jika user ingin membeli jamur harus mendaftar dan memiliki akun terlebih dahulu.

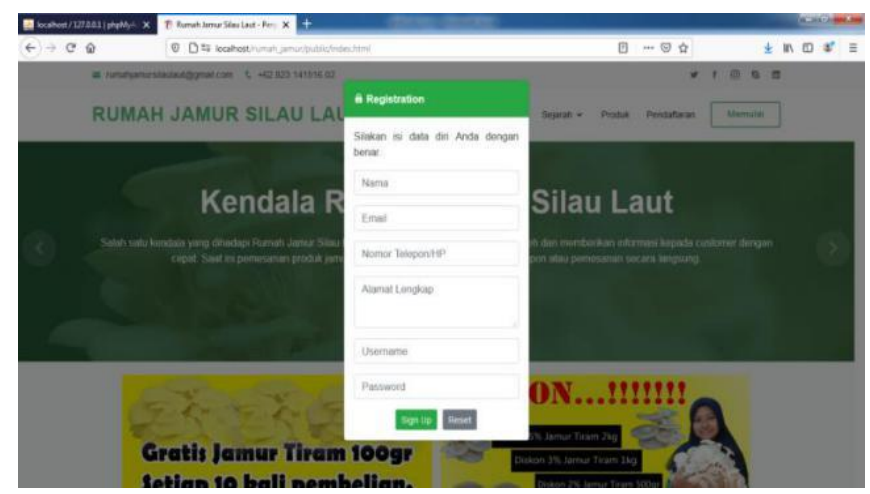

Gambar 1. Daftar akun

\section{Tampilan Data Produk dan Data Pelanggan}

Halaman ini menampilkan output dari data produk yang disimpan ke dalam database. Sedangkan data pelanggan halaman ini menampilkan data pelanggan.

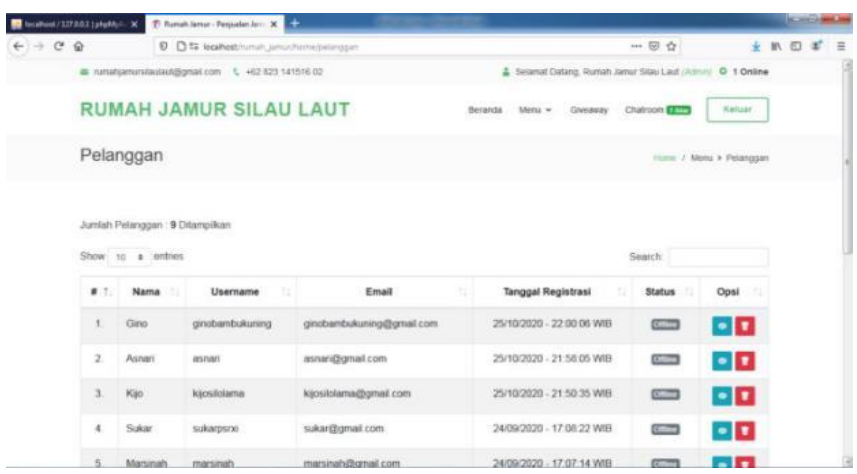

Gambar 2. Tampilan Data Pelanggan 
Vol. 1 No. 1, Feb 2021, hlm. 45 - 50

DOI: https://doi.org/10.33330/.v1i1.1028

Available online at http:// jurnal.stmikroyal.ac.id/index.php/jutsi

\section{Menu Cart}

Halaman ini berisi data produk yang dipesan pelanggan.

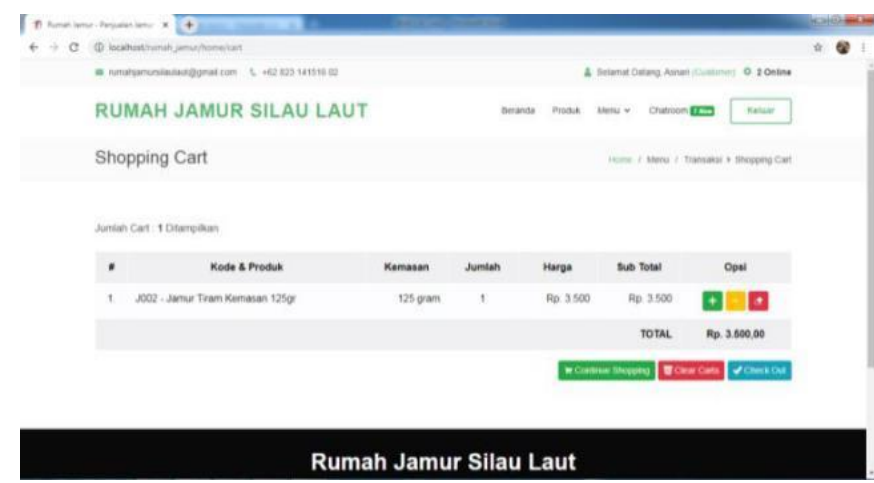

Gambar 3. Tampilan Menu Chart

\section{Menu Checkout}

Setelah melakukan pemesanan maka pelanggan melakukan check out produk yang dipesan.

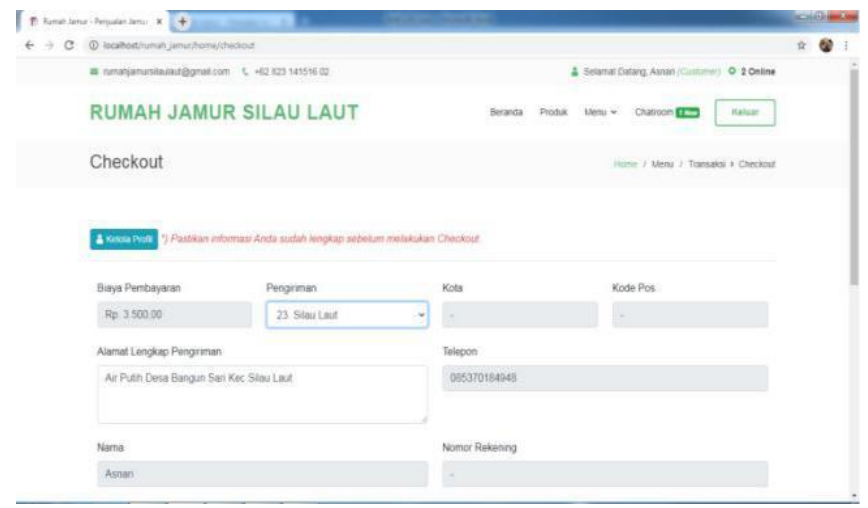

Gambar 4. Menu Checkout

\section{Menu Transaksi}

Setelah melakukan checkout maka pelanggan melakukan transaksi.

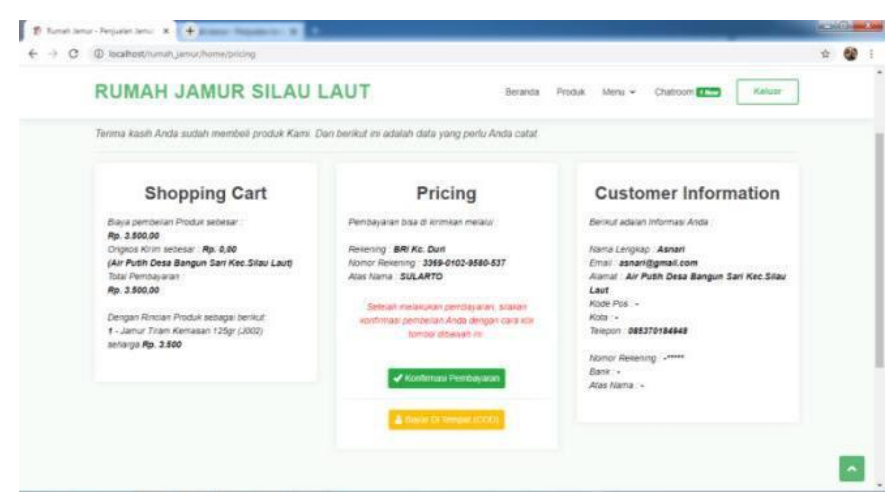

Gambar 5. Menu Transaksi 
Vol. 1 No. 1, Feb 2021, hlm. 45 - 50

DOI: https://doi.org/10.33330/.v1i1.1028

Available online at http:// jurnal.stmikroyal.ac.id/index.php/jutsi

\section{Menu Input Bukti Pembayaran}

Setelah melakukan transaksi maka pelanggan menginputkan bukti pembayaran.

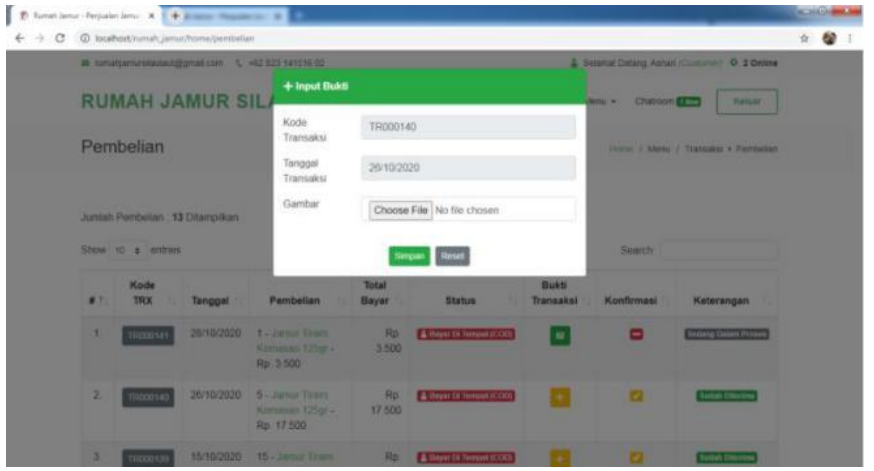

Gambar 6. Menu Input Bukti Pembayaran

\section{SIMPULAN}

Sistem penjualan online dengan menggunakan bahasa pemrograman $P H P$ dan $M y S Q L$ sebagai database server dapat memudahkan pelanggan dalam hal pemesanan jamur dan juga menerapkan Customer Relationship Management yang membantu pemilik untuk berkomunikasi langsung kepada pelanggan lewat fitur-fitur CRM seperti media chat, rating kepuasan terhadap produk atau pelayanan sedangkan bagi pelanggan memudahkan pelanggan untuk melakukan pendaftaran akun, melakukan pemesanan dan pembayaran serta memberikan diskon dan give away kepada pelanggan yang menarik perhatian pelanggan dan menambah pelanggan baru.

\section{DAFTAR PUSTAKA}

[1] I. A. K. MARINI, I. A. NOPIARI, and I. B. EKA ARTIKA, "Analisis Strategi Pemasaran Jamur Tiram Putih (Pleurotus Ostreatus) Pada Usaha Dagang Kenanga Di Kecamatan Ampenan Kota Mataram," Ganec Swara, vol. 13, no. 2, p. 375, 2019, doi: 10.35327/gara.v13i2.105.

[2] Y. O. Rahmawati, A. Kusniawati, and I. Setiawan, "Customer reationship managemet dan," vol. 1, pp. 102-115, 2019.

[3] E. Rahayu, W. M. Kifti, S. Informasi, and S. Royal, "Customer Relationship Management (CRM) Dan Pengaruhnya Terhadap Loyalitas Pelanggan ( Studi Kasus Pada Pelanggan Pt . Cgm Indonesia Kisaran Center )," vol. 9986, no. September, 2018.

[4] A. Dwikanthi and H. Irawan, "Penerapan Electronic Customer Relationship Management (E-Crm) Guna Meningkatkan Loyalitas Pasien Rumah Sakit," J. Komputasi, vol. 7, no. 2, pp. 88-105, 2019, doi: 10.23960/komputasi.v7i2.2428.

[5] Y. B. Utomo, W. W. Winarno, and A. Amborowati, "PERANCANGAN CUSTOMER RELATIONSHIP MANAGEMENT PADA KLINIK (Studi Kasus: Klinik Pratama Nusa Medika Meritjan)," Multitek Indones., vol. 10, no. 1, p. 57, 2016, doi: 10.24269/mtkind.v10i1.239. 